University of Nebraska - Lincoln

DigitalCommons@University of Nebraska - Lincoln

Faculty Publications, Department of Psychology

Psychology, Department of

2011

Heterogeneity of Individuals with a History of Child Sexual Abuse: An Examination of Children Presenting to Treatment

C. Thresa Yancey

Georgia Southern University, tyancey@georgiasouthern.edu

David J. Hansen

University of Nebraska-Lincoln, dhansen1@unl.edu

Karen Z. Naufel

Georgia Southern University, knaufel@georgiasouthern.edu

Follow this and additional works at: https://digitalcommons.unl.edu/psychfacpub

Part of the Psychiatry and Psychology Commons

Yancey, C. Thresa; Hansen, David J.; and Naufel, Karen Z., "Heterogeneity of Individuals with a History of Child Sexual Abuse: An Examination of Children Presenting to Treatment" (2011). Faculty Publications, Department of Psychology. 547.

https://digitalcommons.unl.edu/psychfacpub/547

This Article is brought to you for free and open access by the Psychology, Department of at DigitalCommons@University of Nebraska - Lincoln. It has been accepted for inclusion in Faculty Publications, Department of Psychology by an authorized administrator of DigitalCommons@University of Nebraska - Lincoln. 
Published in Journal of Child Sexual Abuse 20 (2011), pp. 111-127;

doi: 101080/10538712.2011.554341 Copyright (C) Taylor \& Francis Group, LLC.

Used by permission.

Submitted April 7, 2010; revised July 3, 2010; accepted July 16, 2010.

TREATMENT AND PRACTICE ISSUES

\title{
Heterogeneity of Individuals with a History of Child Sexual Abuse: An Examination of Children Presenting to Treatment
}

\author{
C. Thresa Yancey \\ Georgia Southern University, Statesboro, Georgia, USA \\ David J. Hansen \\ University of Nebraska-Lincoln, Lincoln, Nebraska, USA \\ Karen Z. Naufel \\ Georgia Southern University, Statesboro, Georgia, USA \\ Corresponding author - C. Thresa Yancey, Department of Psychology, \\ Georgia Southern University, PO Box 8041, Statesboro, GA 30640-8041; \\ email tyancey@georgiasouthern.edu
}

\begin{abstract}
The current study examined children and families who presented for treatment through Project SAFE (Sexual Abuse Family Education) following childhood sexual abuse. Pretreatment assessment data were used to develop clusters of participants with significantly differing presentation of symptom outcome following abuse. Four clusters were discovered: (a) a Highly Distressed group, whose members had clinically elevated scores on all self- and parent-report measures; (b) a Problem Behaviors group, whose members had scores within the normal range for self-report measures and elevated scores on all parent-report measures; (c) a Subclinical group, whose participants had scores below the mean and below cutoff scores for all self- and parent-report measures; and (d) a Self-reported Distress group, whose members had elevated scores on self-report measures and scores below clinical cutoffs for all parent-report measures.
\end{abstract}

Keywords: child sexual abuse, outcomes, symptoms, child maltreatment 
The public has become more aware of childhood sexual abuse (CSA) and the possible effects of sexual abuse on children through efforts from advocacy groups as well as the use of research data in recent political legislation and popular press reports. Recent reports have placed the number of identified CSA victims at 56,460 children during the year 2007 in the United States (U.S. Department of Health and Human Services, Administration on Children, Youth, and Families, 2009). Jones, Finkelhor, and Kopiec (2001) noted that there was a $39 \%$ decline in substantiated cases of childhood sexual abuse during the 1990s. This decline has also been noted during the first decade of the century (2003-2008), with a decline in children experiencing sexual assault (Finkelhor, Turner, Ormrod, \& Hamby, 2010). In the past, research estimates of the prevalence of CSA prior to age 18 ranged from $27 \%$ to $32 \%$ for females and $13 \%$ to $16 \%$ for males (Berliner \& Elliott, 1996). Based on research on adults, Leventhal (2001) estimated that less than $10 \%$ of CSA is reported to professionals. Given the recent trends of declining substantiated abuse cases, it seems likely that retrospective reports of CSA will also decline.

Unfortunately, the way that researchers define CSA affects the estimates of the number of children who experience CSA. There are no universal definitions of what constitutes CSA in research, treatment, or even among legal definitions (Haugaard, 2000). For example, lawyers, professionals, and scholars alike disagree on a universal definition of CSA regarding multiple facets, including what age range denotes childhood, what acts are sexual in nature, and how one determines the intent of the "perpetrator" (Goldman \& Padayachi, 2000; Haugaard, 2000). While laws offer legal definitions for CSA, methods of data collection and criteria regarding what is conclusively a substantiated case of CSA vary from state to state and country to country (Jones et al., 2001; Leventhal, 2001). This lack of a cohesive definition for CSA can make research in this area ambiguous.

\section{Outcomes Following Child Sexual Abuse}

Despite these definitional difficulties, researchers have established possible patterns of outcomes following CSA. Some researchers have grouped outcomes broadly into internalizing, externalizing, and asymptomatic responses (see Kendall-Tackett, Williams, \& Finkelhor, 1993, for a review). Internalizing symptoms include symptoms of depression, anxiety, post-traumatic stress disorder (PTSD), as well as self-harm behaviors and low self-esteem (e.g., Kendall-Tackett et al., 1993; Paolucci, Genuis, \& Violato, 2001). Externalizing outcomes include conduct problems, aggressive behaviors, and sexual behaviors (Paolucci et al., 2001). Many researchers agree that while children display varied responses to CSA, there are those who show limited or no negative 
outcomes (Kendall-Tackett et al., 1993). The meta-analysis by Kendall-Tackett and colleagues also suggested that victims of CSA demonstrate a tendency to return to pre-abuse functioning on many dimensions within 18 months postdisclosure.

Some moderating factors have been incorporated into comprehensive models of traumatization proposed by researchers (e.g., Conte \& Schuerman, 1987; Finkelhor \& Browne, 1985; Kendall-Tackett et al., 1993) as explanations for outcomes following CSA. In one model, Finkelhor and Browne hypothesized that there are four components to trauma that a victim experiences following CSA. These four components include powerlessness, traumatization related to early sexualization, stigmatization, and betrayal. In another model, Conte and Schuerman postulated that aspects of the abuse as well as other family dysfunction contribute to the trauma that the victim experiences. Furthermore, Conte and Schuerman hypothesized that family dynamics surpass abuse-related factors in their impact on victim outcomes following CSA. Together, these researchers have suggested that the impact of CSA is complicated due to multifaceted outcomes (Kendall-Tackett et al., 1993; Paolucci et al., 2001).

The previous studies have suggested that CSA victims are a heterogenic group, varying in age, ability level, socioeconomic status, education, gender, and outcome following abuse, which may in turn result in different outcomes. In many studies, victims of CSA have been studied as one sample, which does not take into consideration these differences. The current study examines ways in which CSA victims are heterogeneous related to outcome (symptom presentation) following abuse. That is, we examined the unique subgroups in a sample of children with a CSA history presenting to a group treatment program.

\section{Context for the Study}

Project SAFE (Sexual Abuse Family Education) is a 12-week psychoeducational group treatment program for victims of CSA and their nonoffending caregivers. This group treatment and research project has been ongoing since 1996. The current study utilized archival data from past rounds of group treatment. All treatment participants complete a comprehensive assessment battery to assist in investigating the impact of CSA on the victim and the family and to assess the impact of the treatment on the participants. Therapists trained in the delivery of the manualized treatment conduct Project SAFE, but the therapists are also allowed the flexibility to address specific problems that the group members raise in session. Separate groups are conducted concurrently for children and parents. There are two basic divisions for the victims' groups: a children's group and an adolescents' group. 
There are no formal age cutoffs; however, the children's group typically includes children ages 7 to 12 , whereas the adolescent group usually includes those ages 13 to 16 . Groups meet for 90 -minute sessions for 12 consecutive weeks, covering 10 modules. The same topics are covered in the sessions for youths and parents, incorporating education and prevention strategies. Procedures used in sessions are psychoeducation, skill-building, problem-solving, and support.

Previous research using multiple child- and parent-report instruments has documented the positive impact of Project SAFE (Hansen, Hecht, \& Futa, 1998; Hsu, Sedlar, Flood, \& Hansen, 2002; Tavkar \& Hansen, 2010). Results have shown posttreatment improvements in a variety of areas of child behavior and functioning, including less anxiety, less posttraumatic stress symptoms, increased self-esteem, less externalizing behavior problems, increased basic sexual knowledge, less negative perceptions of social reactions, and less maladaptive abuse attributions (Campbell et al., 2006; Hsu, 2003; Sawyer et al., 2005). Three-month follow-up assessments support the continuity of treatment gains. Improvements have also been documented using weekly child and parent reports of emotion and problem behaviors (Sawyer \& Hansen, 2010). Parent and child participants have reported that treatment goals, procedures, and outcomes were relevant, acceptable, and helpful to the families (Hsu, 2003; Sawyer et al., 2005).

To examine the unique symptom presentation of subgroups of victims participating in Project SAFE, clusters of participants were created based on selfand parent-report measures of internalizing and externalizing behaviors. It was expected, based on results in available literature and previous examination of Project SAFE participants (Sedlar, 2001), that the victims assessed as part of the Project SAFE program would present with varied outcomes following CSA. The pretreatment assessment results from parent- and self-report measures were examined to determine which group characteristics differentiated the participants. It was expected that the participants would form four groups, similar to early results found by Sedlar. Specifically, it was hypothesized that the victims and their parents would report outcomes that fall into four categories: (a) internalizing problems (including PTSD symptoms and negative attributions related to the abuse), (b) externalizing problems, (c) highly distressed (i.e., elevated scores on all measures), or (d) subclinical outcomes.

\section{Method}

\section{Participants}

All participants presented for treatment in the Project SAFE program and consented to complete assessment measures. Families were recruited to the treatment and study via the community. The primary source for the 
dissemination of information regarding Project SAFE was a child advocacy center (CAC) in Nebraska. Other families participating in Project SAFE were recruited through the Department of Health and Human Services, as well as through other professionals who treat sexually abused children and adolescents. Due to various circumstances, there were children and adolescents who participated without a caregiver (e.g., the child was in foster care, the parent's work schedule did not permit their attendance) and parents who participated without their child (e.g., their child was too young; their child was in foster care). Also, some parents participated in Project SAFE with multiple children who had been sexually abused. Only one child and one parent/caregiver from each family were used in analyses. Due to a smaller percentage of male participants in the sample, when available, a male sibling was selected over a female sibling. In the cases where both or all siblings were of the same gender, the oldest sibling was selected. In the cases where all siblings were the same age and gender, the child listed first was selected. Overall, 26 participants were eliminated from the total sample due to having a sibling who had also participated in Project SAFE. This left 101 participants for the current study.

Of the 101 child participants, 19 were boys $(18.8 \%)$, and 82 were girls $(81.2 \%)$. Ages ranged from 7 to 16.75 years $(M=11.74, S D=2.68)$ at the time of the initial assessment. Child participants were primarily Caucasian $(n=78$; $77.2 \%)$, with eight African American (7.9\%)), seven biracial (6.9\%), three Hispanic $(3.0 \%)$, three American Indian (3.0\%), and one multiracial (1.0\%) participant. There was one child participant $(1.0 \%)$ for whom racial identity was unknown. Most parents who participated were women $(n=84 ; 83.2 \%)$ and the biological mother of the child $(n=77 ; 76.2 \%)$. Other caregivers included biological fathers $(n=14 ; 13.9 \%)$, foster mothers $(n=4 ; 4.0 \%)$, grandmothers $(n=2 ; 2.0 \%)$, step/adoptive mothers $(n=1 ; 1.0 \%)$, and "other caregiver" $(n$ $=3 ; 3.0 \%)$. Parent participants ranged in age from 23 to 72 years $(M=36.15$, $S D=7.41)$. Similar to the child participants, parent participants were primarily Caucasian $(n=86 ; 85.1 \%)$, with four biracial $(4.0 \%)$, three African American $(3.0 \%)$, two Hispanic (2.0\%), and one American Indian (1.0\%) participant. There were five parent participants for whom racial identity was unknown (5.0\%). Demographic data are summarized in Table 1.

To be included in this study, the case had to meet the following criteria: (a) the child was between the ages of 7 and 17 at the time of the initial assessment, $(b)$ the nonoffending parent assumed a caregiving role within the family (e.g., stepparent, foster parent, grandparent), and (c) protective services investigated the allegation. There were no restrictions applied to the victimperpetrator relationship, victim gender, gender of the caregiver attending, or gender of the perpetrator. The only exclusionary criteria were significantly impaired cognitive/intellectual functioning of the child or parent. These families were offered individual services at no charge. 
Table 1. Demographic Information

\begin{tabular}{|c|c|c|}
\hline & Frequency & Percentage \\
\hline \multicolumn{3}{|l|}{ Gender (child) } \\
\hline Male & 19 & 18.8 \\
\hline Female & 82 & 81.2 \\
\hline \multicolumn{3}{|l|}{ Gender (adult) } \\
\hline Male & 14 & 13.9 \\
\hline Female & 84 & 83.2 \\
\hline \multicolumn{3}{|l|}{ Race/Ethnicity (child) } \\
\hline African American & 8 & 7.9 \\
\hline Biracial & 7 & 6.9 \\
\hline Caucasian & 78 & 77.2 \\
\hline Hispanic & 3 & 3.0 \\
\hline Multiracial & 1 & 1.0 \\
\hline Native American & 3 & 3.0 \\
\hline Unknown & 1 & 1.0 \\
\hline \multicolumn{3}{|l|}{ Race/Ethnicity (adult) } \\
\hline African American & 3 & 3.0 \\
\hline Biracial & 4 & 4.0 \\
\hline Caucasian & 86 & 85.1 \\
\hline Hispanic & 2 & 2.0 \\
\hline Native American & 1 & 1.0 \\
\hline Unknown & 5 & 5.0 \\
\hline \multicolumn{3}{|l|}{ Relationship to Child } \\
\hline Biological Mother & 77 & 76.2 \\
\hline Biological Father & 14 & 13.9 \\
\hline Foster Parent & 4 & 4.0 \\
\hline Grandmother & 2 & 2.0 \\
\hline Step/adoptive mother & 1 & 1.0 \\
\hline \multirow[t]{2}{*}{ Other } & 3 & 3.0 \\
\hline & Mean & Standard deviation \\
\hline Age (child) & 11.74 & 2.68 \\
\hline Age (adult) & 36.15 & 7.41 \\
\hline
\end{tabular}

\section{Child-Report Measures}

The following child instruments (listed in alphabetical order) were utilized in the present study.

Children's Depressive Inventory (CDI)

The CDI (Kovacs, 1992) is a 27-item measure utilized with children and adolescents (ages 7 to 17) that assesses a range of depressive symptomatology. It is the most widely used measure for the assessment of depressive symptoms in children and adolescents, for both clinical and research purposes. The CDI is designed to assess the level of agreement from the respondent with a statement regarding his or her attitudes over the past two-week period. It has good internal consistency ( $r=.71$ to .89 ) and acceptable temporal stability. 


\section{Children's Impact of Traumatic Events-Revised (CITES-R)}

The Children's Impact of Traumatic Events-Revised (Wolfe, Gentile, Michienzi, Sas, \& Wolfe, 1991) is a structured interview for use with children ages 8 to 16. It measures the impact of sexual abuse from the child's perspective (i.e., thoughts and feelings about what happened to them) across areas of posttraumatic stress, abuse attributions, social reactions, and eroticism. Chaffin and Shultz (2001) found that internal consistencies for the scales averaged .69. The four main scales yielded alpha coefficients of .78 (Abuse Attributions), .87 (Social Reactions), .88 (PTSD), and .57 (Eroticism; Wolfe et al., 1991).

\section{Revised Children's Manifest Anxiety Scale (RCMAS)}

The RCMAS (Reynolds \& Richmond, 1985) is a 37-item self-report questionnaire designed for children and adolescents ages 6 to 19. This scale is designed to assess general anxiety symptoms by having respondents answer yes-or-no questions. The RCMAS yields three subscale scores for Physiological Anxiety, Worry/Oversensitivity, and Social Concerns/Concentration. There is also a Total Anxiety Score and a Lie Scale, which determines a child's defensiveness or inability to understand the questions. Reliability coefficients for the RCMAS are 83 (Reynolds \& Richmond, 1985).

\section{Parent-Report Measures}

The following parent instruments were used in the present study.

\section{Demographic Questionnaire}

The demographic questionnaire was designed specifically for this project to collect general information about the family members. Specific information about the parents includes marital status, ethnic background, employment status, family income, highest degree attained, and age. Information about the child includes age, ethnic background, current school, and current grade.

\section{Child History Form (CHF)}

The Child History Form is an unstructured interview that collects relevant abuse-related information. The CHF is completed by one of the Project SAFE staff members as parents provide information about the abuse in their own words. Abuse characteristics gathered include age at onset and end of abuse, abuse duration and frequency, victim/perpetrator relationship, number of times abused, characteristics of the abuse, and intrusiveness of abuse (i.e., whether penetration occurred). These data were coded by research assistants at the time of data entry. 


\section{Child Behavior Checklist (CBCL)}

The Child Behavior Checklist-Parent Report Form (Achenbach, 1991) is a 113-item checklist used for the assessment of parents' perceptions of social competence and behavioral problems of their children. It is designed for use with parents of children between the ages of 4 and 18. Parents are asked to rate the incidence of problem behaviors observed in the previous six months on a three-point scale ranging from 0 (not true) to 2 (very true or often true). The CBCL scales have been standardized, taking into account age and gender. The CBCL is a widely used instrument with well-established reliability and validity (Achenbach, 1991).

\section{Child Sexual Behavior Inventory (CSBI)}

The Child Sexual Behavior Inventory (Friedrich et al., 2001) is a 35-item inventory completed by parents on the frequency of various sexual behaviors including sexual aggression, self-stimulation, gender-role behavior, and personal boundary violation observed in their children ages 2 to 12 . The CSBI demonstrates adequate reliability (e.g., alpha coefficient of .72 for a normative sample and .93 for a clinical sample of children with a confirmed history of sexual abuse) and discriminant validity (Friedrich et al., 2001).

\section{Results}

\section{Preliminary Analyses}

Prior to analyzing the data to test the hypotheses, the data were examined to describe more fully the abuse experienced by the participants of the current study. The average age of the perpetrator was $29.16(S D=13.66)$, and the perpetrators were primarily male $(n=94,93.1 \%$; female: $n=6,5.9 \%$; unknown: $n=1,1.0 \%)$. Most victims ( $n=85,84.2 \%)$ had one perpetrator, while 12 had two (11.9\%), and three victims had three perpetrators $(3.0 \%)$. Most victims were abused only one time $(n=37,36.6 \%)$, but a large minority were abused an unknown number of times $(n=23,22.8 \%)$. Most victims disclosed their abuse $(n=71,70.3 \%)$, while only four victims had a perpetrator who disclosed the abuse (4.0\%). Many victims experienced multiple forms of abuse, and $22(21.8 \%)$ had perpetrators who used force during the abuse. Most $(42 \%)$ of participants were abused by a parent or parent figure (stepparent or partner of parent). Others were abused by another relative (21\%); a teacher, coach, or babysitter $(18 \%)$; a peer $(16 \%)$; and/or a stranger $(3 \%)$.

\section{Cluster Analysis}

Youth self-reports and parental reports were utilized to determine which profile best described outcome symptoms at the time of initial assessment. A 
cluster analysis using scores from the CDI, the RCMAS, the PTSD subscale of the CITES, the Internalizing and Externalizing Behavior Scales from the CBCL-Parent Report, and the Total Score from the CSBI was conducted. The cluster analyses were created using Ward's method and Squared Euclidean Differences, and they were examined to discover the most consequential interpretation of the data as well as the most meaningful profiles of the youth.

Cluster analysis groups individuals with similar scores on the measures. This analysis differs from other classification procedures by generating clusters when group membership is unknown. The hierarchical agglomerative method of clustering, which is commonly used in the social sciences (Tabachnick \& Fidell, 1996), was chosen to cluster youth according to scores on the five measures. Before analysis, all subscale $t$-scores and standardized scores were converted to $z$-scores to eliminate any possible conflicts due to standardization differences among the measures. Ward's method was chosen for analysis because it minimizes within-cluster variance, which results in relatively homogeneous groups (Aldenderfer \& Blashfield, 1984). The similarity between cases was measured by using the squared Euclidean distance. The squared Euclidean distance method of measuring similarity is consistent with other commonly used analyses (i.e., variance and covariance) that also calculate squared distances (Aldenderfer \& Blashfield, 198,4).

In cluster analysis, there are no collectively agreed on criteria for deciding what number of clusters to maintain. Generally, an amalgamation of procedures is employed, starting with the examination of the agglomeration schedule to assess significant changes in coefficient. values (Aldenderfer \& Blashfield, 1984). The percentage of change between coefficients from one stage of clusters to the next in the agglomeration was examined. The increase in within-cluster variability was less than $11 \%$ prior to the stage in which five clusters were combined to form four. This stage demonstrated within-cluster variability that resulted in a $15.2 \%$ increase, suggesting that a four-cluster solution was the best fit.

Following inspection of the agglomeration schedule, linear discriminant function analyses (LDFs) using the $z$-scores of the CDI, RCMAS, CITES PTSD scale, CBCL Internalizing and Externalizing scales, and CSBI were conducted. These analyses suggested that there were two significant discriminant functions with a combined $x^{2}(18, N=101)=207.306, p<.0001$. Following the removal of the first function, the combined second and third functions were significant with a combined $\chi^{2}(10, N=101)=82.197, p<.0001$. Following the removal of the second discriminant function, the third was not significant but approached significance with $\chi^{2}(4, N=101)=9.335, p=.053$. Due to other evidence for keeping four clusters (i.e., examination of the agglomeration schedule, review of the literature, the third function was approaching significance, evidence from a prior study using a smaller sample of Project 
Table 2. Classification of Cluster Members

\begin{tabular}{lcccc}
\hline \multicolumn{4}{c}{ Predicted cluster membership } \\
\hline Original membership & $\begin{array}{c}\text { Highly } \\
\text { distressed }\end{array}$ & $\begin{array}{c}\text { Problem } \\
\text { behaviors }\end{array}$ & Subclinical & $\begin{array}{c}\text { Self-reported } \\
\text { distress }\end{array}$ \\
\hline Highly Distressed $(N=21)$ & $100.0 \%(21)$ & $0.0 \%(0)$ & $0.0 \%(0)$ & $0.0 \%(0)$ \\
Problem Behaviors $(N=36)$ & $2.8 \%(1)$ & $94.4 \%(34)$ & $2.8 \%(1)$ & $0.0 \%(0)$ \\
Subclinical $(N=12)$ & $0.0 \%(0)$ & $0.0 \%(0)$ & $100.0 \%(12)$ & $0.0 \%(0)$ \\
Self-Reported Distress $(N=32)$ & $0.0 \%(0)$ & $6.3 \%(2)$ & $0.0 \%(0)$ & $93.8 \%(30)$ \\
\hline
\end{tabular}

$96.0 \%$ of cases reclassified correctly.

SAFE participants [Sedlar, 2001]), four clusters were kept despite the failure of the third discriminant function to reach significance. The three-cluster solution led to a loss of those self-identifying as having depressive and anxious symptoms whose parents were not reporting difficulties for their child. These children were subsumed into the group with subclinical responses (with a higher mean score on self-report measures for the cluster), which does not offer the true picture of the outcomes for these children. The first function accounted for $68.5 \%$ of the between-groups variability, the second accounted for $28.9 \%$, and the third accounted for $2.6 \%$. Discriminant functions correctly classified $100.0 \%$ of the first group, $94.4 \%$ of the second group, $100.0 \%$ of the third group, and $93.8 \%$ of the fourth group with an overall correct classification rate of $96.0 \%$. The classification data are shown in Table 2.

The mean scores for each cluster on the measures used to create the clusters are displayed in Figure 1. The first cluster was labeled Highly Distressed and contained 21 participants with a mean age of 11.66 years $(S D=2.58)$. Of the 21 participants in the Highly Distressed group, four were male and 17 were female. This group was named Highly Distressed due to significantly elevated scores on both self-report measures and parent-report measures. The second was labeled Problem Behaviors and contained 36 participants, of which 10 were male and 26 were female. The mean age of those in the Problem Behaviors group was 11.65 years $(S D=2.77)$. The label Problem Behaviors was used because these participants were characterized by significantly elevated scores on parent-report measures with scores on self-report measures that fell below the mean. The third, containing 12 participants, was labeled Subclinical and had two male and 10 female participants. The mean age for the Subclinical group was 10.90 years $(S D=2.49)$. These participants had scores below the mean for all measures. The fourth group, with 32 participants, was labeled Self-Reported Distress and had a mean age of 12.20 years $(S D=2.74)$. In the Self-Reported Distress group there were three male and 29 female participants. These participants had self-report scores that were above the mean and parent-report scores that were below the mean. 


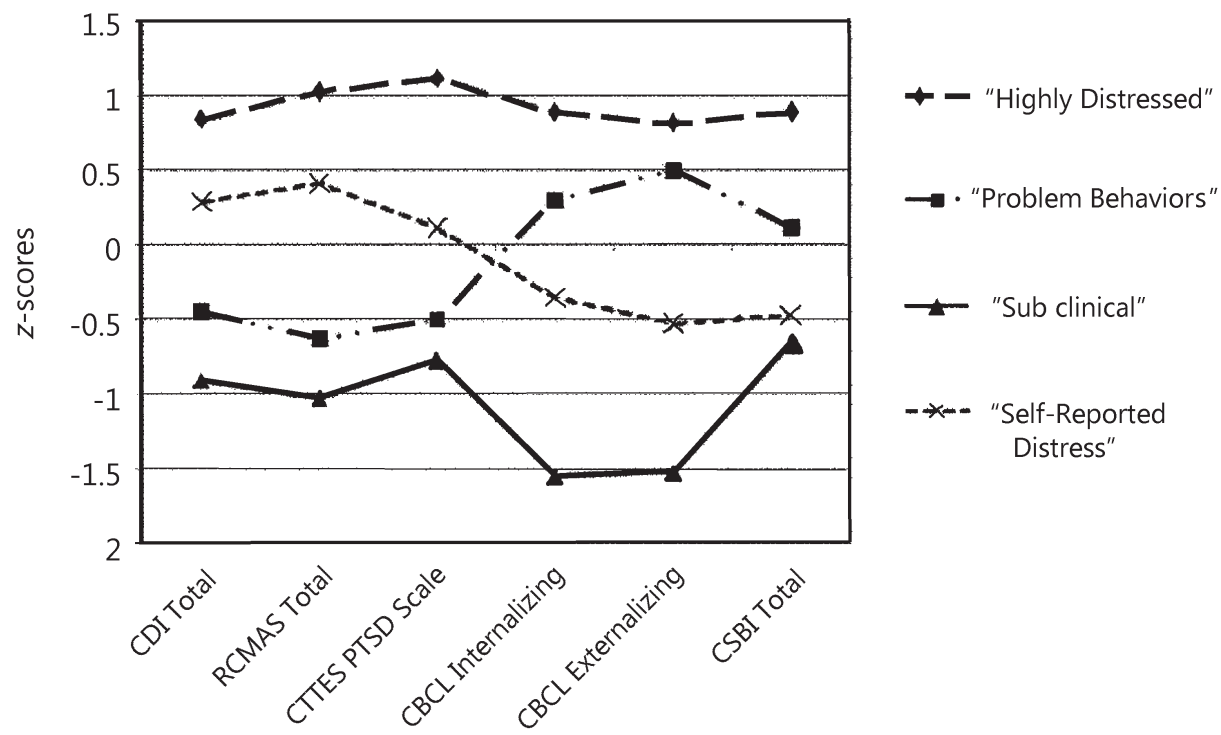

Figure 1. Clinical profiles (based on z-scores) of self-report and parent-report measures.

\section{Discussion}

The four groups - Highly Distressed, Problem Behaviors, Subclinical, and Self-Reported Distress-demonstrated unique symptomatology as reported on the CDI, CITES-PTSD, RCMAS, CBCL, and CSBI. Prior studies have suggested that individuals who have experienced CSA present with internalizing symptoms, externalizing symptoms, both internalizing and externalizing symptoms, or as asymptomatic (Kendall-Tackett et al., 1993). The current study did not find evidence to dispute these categories; instead, the findings suggest that these labels may be too simplistic to accurately describe the outcomes experienced. As predicted, four distinct clusters of victims of CSA were discovered. The Highly Distressed group was composed of individuals who self-reported many clinical symptoms as well as having parental report of multiple difficulties. This group most likely corresponds to those labeled both internalizing and externalizing. For this group, the participants were reporting symptoms of anxiety, depression, and PTSD, and the parent report indicated symptoms in these areas as well as externalizing behaviors (including sexualized behaviors).

The Problem Behavior group was characterized by low scores (fewer endorsed symptoms) on self-report measures and high scores (more endorsed symptoms) on parent-report measures of both internalizing and externalizing symptoms. This group may represent what prior researchers have labeled as externalizing, as the parents of these participants reported significant difficulties in many areas and may attribute some of these behavior difficulties to 
internalizing problems (e.g., depression, anxiety) even though the victim did not self-endorse difficulties related to internalizing problems. In other words, these participants may be seen as needing more services by those around them such as their parents, since the behaviors displayed may cause distress to their families and other caregivers. There is support for this hypothesis in the literature, as Loeber, Green, and Lahey (1990) found that clinicians give greater weight to parental report of externalizing problems and more credence to the child's report of internalizing difficulties. Furthermore, Frick, Silverthorn, and Evans (1994) found that parental reports of child anxiety were more related to the parent's own anxious symptoms.

The Self-Reported Distress cluster consisted of participants who self-reported internalizing symptoms but whose parents did not endorse significant difficulties in their child. This group likely corresponds most closely to the internalizing outcomes presented by other researchers. There is research to suggest that parents are not always accurate reporters of their children's internalizing difficulties (Comer \& Kendall, 2004; Sourander, Helstela, \& Helenius, 1999). These participants may have parents who do not recognize internalizing symptoms in their children. The nature of internalizing difficulties compared to externalizing problems may make these symptoms less salient to parents. Children's symptoms of depression and anxiety may be less noticeable than externalizing symptoms such as oppositional and aggressive behaviors and therefore may not be recognized by adults caring for the child.

Finally, the Subclinical cluster likely reflects the asymptomatic label, as these participants and their parents did not endorse symptoms on measures of internalizing or externalizing difficulties. These participants had scores on all measures that were below the cutoff for the measures and below the mean for the study sample. These children may have protective factors that prevented any negative symptom development at the time of assessment. These protective factors could be within the child (resiliency, attribution of blame to the perpetrator, therapeutic intervention, etc.), within the family (parental or other adult support, strong social support, etc.), or related to the abuse situation (immediate intervention, etc.). Of these, several are amenable to treatment and give direction to further study and implications for treatment for those that do display symptomatology.

The use of multiple informants and comprehensive clinical measures during assessment was a particular strength of the current study. Data on internalizing symptoms were collected from both the child victim and a parent figure. The use of multiple informants allowed for input from the victim and from someone with close contact to the victim. As one might imagine, there were discrepancies between informants that led to interesting patterns in symptom presentation following CSA. For example, some children in the current study did not self-report difficulties that their parents observed. There 
are many reasons for the discrepancies between informants, including the fact that parents are not always accurate reporters of their children's internalizing symptoms and the fact that parents may attribute internalizing difficulties to outward behavioral problems (Comer \& Kendall, 2004; Sourander et al., 1999). These discrepancies led to a group of participants, labeled Problem Behaviors, whose parents reported significant difficulties in internalizing and externalizing difficulties while the victim reported no clinically significant distress. It seems, therefore, that these children are likely displaying behaviors that are problematic for those around them. Past studies have not reported a category of this nature among victims of CSA. Also, data were collected in areas that the research has indicated to be important for CSA victims, including internalizing and externalizing symptoms. Furthermore, data were available for sexual behavior concerns, which is often an area that is neglected in other studies.

The greatest strength of the current study may be that comprehensive data were available for the participants in the study. Many past studies have reported limited information on the types of abuse experienced. This project, perhaps as a result of the incorporation of data collection with treatment services, was able to collect significant data regarding symptomatology, abuse characteristics, and information on parent and family functioning, among other areas. Furthermore, the current sample of 101 participants is large compared to many studies in the literature. This is especially true of studies that have utilized data collected from children (e.g., Mian, Marton, \& LeBaron, 1996, who examined 70 female victims; Nelson, Moser, Johnson, Graves, \& Hart, 1999, who examined 25 female victims; Young, Bergandi, \& Titus, 1994, who examined 40 victims) as opposed to retrospective adult studies (e.g., King, Coxell, \& Mezey, 2002, who studied 2,545 men).

Additionally, many researchers do not investigate victims who show asymptomatic responses following CSA. This study aimed to be more comprehensive than past studies by using multiple informants to describe outcome following CSA and to include victims that display subclinical outcomes in analyses. The current study demonstrates that there are significant differences in outcome among victims of CSA, and it appears appropriate to differentially examine them since they do not represent a homogenous group.

\section{Limitations of the Current Study}

When studying victims of CSA, there are always difficulties related to definitional issues of CSA, inability to infer causation of outcomes from the abuse, obtaining accurate information regarding the details of the abuse (e.g., severity, duration), and recruitment of participants during a difficult time. There were no exceptions to these difficulties in the current study, with the 
possible exception of the close relationship built with the local child advocacy center and the center's awareness of the importance of research on CSA. This relationship enabled participants to be recruited through a forum that was already familiar and generally well received for the families who participated in Project SAFE. As always, there may be a difference between people who volunteer themselves and their children to participate in research and treatment and those that choose not to participate when recruited. There is no way to assess any potential differences. In addition, the participants of the current study had limited diversity related to gender and ethnicity. Future research should expand to include a greater number of male participants and more representation of other ethnic/racial groups.

\section{Implications and Future Directions}

This study has demonstrated that CSA victims present with varied outcomes. Future research should include replications of the cluster analysis and compare the use of clusters to examining a sample of CSA victims as a homogenous group to assess whether examining subgroups offers advantages over examining the sample as a whole. Furthermore, analyzing a larger sample of victims (including a more diverse sample) as well as victims not presenting to treatment would add to the current study by examining whether these cluster presentations generalize to other populations of CSA victims. While it is often difficult to access victim populations for myriad reasons, this study has demonstrated the importance of creating and maintaining relationships with community agencies and the benefit these relationships can have on accessing victim samples.

The present study's findings also have implications for treatment, including tailoring interventions to individuals based on what type of outcomes are displayed postabuse. This may include having different group treatments within Project SAFE and other treatment services that address the specific type of outcome displayed. Specifically, variable group length based on the severity of symptom presentation is possible, where those that are not displaying negative outcomes (Subclinical group) may benefit from briefer, psychoeducational intervention, and those in the Highly Distressed cluster may benefit from more intensive symptom-focused intervention. Additionally, group membership could be strategically planned to incorporate the strengths of particular groups.

In addition, these findings underscore the potential importance of studying children who display asymptomatic responses to CSA. By examining these victims more thoroughly, researchers can gain insight into resiliency and discover areas to target with treatment. Therapists can use the findings to evaluate and plan treatment more specifically given the outcomes of an individual child. 
In sum, the present study found distinct differences among the victims on outcome measures of both internalizing and externalizing symptoms. These differences yielded four clusters of participants, each with a different presentation of symptoms. This study elucidated the need to treat victims of CSA as a heterogeneous group with marked differences in symptom presentation following abuse. Though this study showed there are distinct differences in outcome presentation among victims, there continue to be unanswered questions regarding the impact of CSA on children. Future research can build on the present research to evaluate the generalizability of the cluster presentations of the current sample and better determine which interventions benefit the different groups the most. Finally, examination of the distinguishing characteristics of the children from each of the present clusters could help explicate possible reasons for differing outcomes among victims of CSA.

\section{References}

Achenbach, T. M. (1991). The Child Behavior Checklist manual. Burlington, VT: The University of Vermont.

Aldenderfer, M. S., \& Blashfield, R K. (1984). Quantitative applications in the social sciences: Vol. 44: Cluster analysis. Thousand Oaks, CA: Sage Publications.

Berliner, L., \& Elliott, D. M. (1996). Sexual abuse of children. In J. Briere \& L. Berliner (eds.), APSAC handbook on child maltreatment (pp. 51-71). Thousand Oaks, CA: Sage Publications.

Campbell, C., Wilson, K., Evans, S., Sawyer, G. K., Tavkar, P., \& Hansen, D. J. (2006, November). Heterogeneity of psychological and behavior symptom presentation in sexually abused youth: Three months post treatment. Poster presented at the annual convention of the Association for Behavioral and Cognitive Therapies, Chicago, IL.

Chaffin, M., \& Shultz, S. (2001). Psychometric evaluation of the Children's Impact of Traumatic Events Scale-Revised. Child Abuse \& Neglect, 25, 401-411.

Comer, J. S., \& Kendall, P. C. (2004). A symptom-level examination of parent-child agreement in the diagnosis of anxious youths. Journal of the American Academy of Child and Adolescent Psychiatry, 43, 878-886.

Conte, J. R, \& Schuerman, J. (1987). The effects of sexual abuse on children: A multidimensional view. Journal of Interpersonal Violence, 2, 380-390.

Finkelhor, D., \& Browne, A. (1985). The traumatic impact of child sexual abuse: A conceptualization. American Journal of Orthopsychiatry, 55, 530-541.

Finkelhor, D., Turner, H., Ormrod, R., \& Hamby, S. L. (2010). Trends in childhood violence and abuse exposure: Evidence from two national surveys. Archives of Pediatrics $\mathcal{E}$ Adolescent Medicine, 164, 238-242.

Frick, P. J., Silverthorn, P., \& Evans, C. S. (1994). Assessment of childhood anxiety using structured interviews: Patterns of agreement among informants and association with maternal anxiety. Psychological Assessment, 6, 372-379.

Friedrich, W. N., Fisher, J. L, Dittner, C. A., Acton, R., Berliner, L., Butler, J., et al. (2001). Child Sexual Behavior Inventory: Normative, psychiatric, and sexual abuse comparisons. Child Maltreatment, 6, 37-49.

Goldman, J. D. G., \& Padayachi, U. K. (2000). Some methodological problems in estimating incidence and prevalence in child sexual abuse research. Journal of Sex Research, 37, 305-315. 
Hansen, D. J., Hecht, D. B., \& Futa, K. T. (1998). Child sexual abuse. In V. B. Van Hasselt \& M. Hersen (eds.), Handbook of psychological treatment protocols for children and adolescents (pp. 153-178). Mahwah, NJ: Erlbaum.

Haugaard, J. J. (2000). The challenge of defining child sexual abuse. American Psychologist, 55, 1036-1039.

Hsu, E. (2003). Parallel group treatment for sexually abused children and their nonoffending parents: An examination of treatment integrity and child and family outcome and satisfaction. PhD dissertation, University of Nebraska-Lincoln.

Hsu, E., Sedlar, G., Flood, M. F., \& Hansen, D. J. (2002). Child sexual abuse. In M. Hersen (ed.), Clinical behavior therapy: Adults and children (pp. 449-473). New York, NY: Wiley.

Jones, L. M., Finkelhor, D., \& Kopiec, K. (2001). Why is sexual abuse declining? A survey of state child protection administrators. Child Abuse \& Neglect, 25, 1139-1158.

Kendall-Tackett, K. A., Williams, L. M., \& Finkelhor, D. (1993). Impact of sexual abuse on children: A review and synthesis of recent empirical studies. Psychological Bulletin, 113, 164-180.

King, M., Coxell, A., \& Mezey, G. (2002). Sexual molestation of males: Associations with psychological disturbance. British Journal of Psychiatry, 181, 153-157.

Kovacs, M. (1992). Children's Depression Inventory. Toronto, Canada: Multi-Health Systems.

Leventhal, J. M. (2001). A decline in substantiated cases of child sexual abuse in the United States: Good news or false hope? Child Abuse \& Neglect, 25, 1137-1138.

Loeber, R., Green, S. M., \& Lahey, B. B. (1990). Mental health professionals' perception of the utility of children, mothers, and teachers as informants on childhood psychopathology. Journal of Clinical Child Psychology, 19, 136-143.

Mian, M., Marton, P., \& LeBaron, D. (1996). The effects of sexual abuse on 3- to 5-year-old girls. Child Abuse \& Neglect, 20, 731-745.

Nelson, W. M., Moser, A., Johnson, N. E., Graves, K., \& Hart, K. J. (1999). Behavioral characteristics of preadolescent girls from sexually abusive vs. dysfunctional families. Psychology: A Journal of Human Behavior, 36, 21-27.

Paolucci, E. O., Genuis, M. L., \& Violato, C. (2001). A meta-analysis of the published research on the effects of child sexual abuse. Journal of Psychology, 1135, 17-37.

Reynolds, C. R., \& Richmond, B. O. (1985). Revised Children's Manifest Anxiety Scale. Los Angeles, CA: Western Psychological Services.

Sawyer, G. K., \& Hansen, D. J. (2010). Heterogeneous symptom patterns of sexually abused youth in treatment: Understanding the complexity of the problem. Manuscript submitted for publication.

Sawyer, G. K., Yancey, C. T., Hsu Tsao, E., Wynne, A., Hansen, D. J., \& Flood, M. F. (2005, November). Parallel group treatments for sexually abused youth and their nonoffending parents: Treatment integrity, outcomes and social validity of Project SAFE. Poster presented at the annual convention of the Association for Behavioral and Cognitive Therapies, Washington, DC.

Sedlar, G. (2001). Heterogeneous clinical presentation of sexually abused youth presenting for treatment: An initial examination of clinical subtypes and correlates of adjustment, PhD dissertation, University of Nebraska-Lincoln.

Sourander, A., Helstela, L., \& Helenius, H. (1999). Parent-adolescent agreement on emotional and behavior problems. Social Psychiatry and Psychiatric Epidemiology, 34, 657-663.

Tabachnick, B. G., \& Fidell, L. S. (1996). Using multivariate statistics (3rd ed.). New York: Harper Collins. 
Tavkar, P., \& Hansen, D. J. (2010), Interventions for families victimized by child sexual abuse: Clinical issues and approaches for child advocacy center-based services. Manuscript submitted for publication.

U.S. Department of Health and Human Services, Administration on Children, Youth, and Families. (2009), Child maltreatment 2007. Washington, DC: U.S. Government Printing Office.

Wolfe, V. V, Gentile, C, Michienzi, T, Sas, L., \& Wolfe, D. A. (1991). The Children's Impact of Traumatic Events Scale: A measure of post-sexual abuse PTSD symptoms. Behavioral Assessment, 13, 359-383.

Young, R. E., Bergandi, T A., \& Titus, T. G. (1994). Comparison of the effects of sexual abuse on male and female latency-aged children. Journal of Interpersonal Violence, 9, 291-306. 